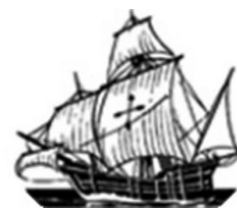

\title{
A literatura infantil e a infância em Menino de
}

\author{
Engenho
}

\author{
Alaim Souza Neto ${ }^{1}$ \\ Geovana Mendonça Lunardi Mendes ${ }^{2}$
}

\begin{abstract}
Resumo: Este ensaio procura problematizar a relação e o potencial da narração e do brinquedo na infância à luz da obra Menino de Engenho de José Lins do Rego, como processos interventivos de caráter positivo para ser criança. O artigo está fundamentado em estudos bibliográficos, fazendo uma abordagem descritiva. No primeiro item, busca-se percorrer o caminho trilhado pela narração até a literatura infantil, este como fonte de apropriação da cultura e na cultura à criança. Entretanto, lastima Benjamin, o hábito de narrar foi sendo perdido até encontrar seu esfacelamento em virtude de uma perda de referências coletivas. Essa perda teria contribuído para o surgimento do romance no final do século XIX. No segundo item, a concepção de infância em Menino de Engenho é o que impulsiona o desenvolvimento do artigo, e tal movimento se dá por meio das relações acentuadas de "poder" do próprio menino de engenho sobre o moleque, as narrativas e a importância do brinquedo na infância, bem como, suas influências na personalidade da criança. A dinâmica da infância daquela época pode ser claramente percebida no livro Menino de Engenho. O último item enfatiza o cruzamento das narrações, brincadeiras, porcarias, depravações e sexo, que o menino de engenho vivencia com a ampla liberdade do latifúndio e na preocupação em "pôr limites", a criança é encaminhada à escola para "correção" e "endireitamento". Assim, problematiza-se a escola e o surgimento da ciberinfância.
\end{abstract}

Palavras-Chave: infância; brinquedo; narração.

\begin{abstract}
This essay aims to discuss the relationship and the potential of storytelling and childhood toy based on the work of José Lins do Rego, Menino de Engenho, as positive interventional procedures to be a child. The article is based on bibliographical studies, making a descriptive approach. In the first item, we seek to follow the path trodden by the narration to children's literature, this one as source of appropriation of culture and in culture to children. However, Benjamin laments the habit of narrating was being lost to find its breakup due to a loss of collective references. This loss

${ }^{1}$ Doutorando do Programa de Pós-Graduação em Educação da UDESC na linha de pesquisa: educação, comunicação e tecnologia. Técnico em Assuntos Educacionais na UFSC. E-mail: alaimsatc@yahoo.com.br

${ }^{2}$ Professora Doutora em Educação e Coordenadora do PPGE - Programa de Pós Graduação em Educação da UDESC. E-mail: geolunardi@gmail.com
\end{abstract}


would have contributed to the emergence of the novel in the late nineteenth century. In the second item, the conception of childhood in Menino de Engenho is what drives the development of the article, and such movement is emphasized by the strong relations of "power" that the boy exerts on the urchin, the narratives and the importance of childhood toy, as well as their influences on child's personality. The dynamics of childhood from that time can be clearly seen in the book Menino de Engenho. The last item highlights the intersection of stories, jokes, filth, depravity and sex, the boy experiences with ample freedom of landlordism and concerning "putting limits", the child is sent to school to "fix" and "straightening ". This way, we problematize the school and the emergence of cyber childhood.

Keywords: children; toy; narration.

\title{
1. Narradores e narrativas: os primórdios da literatura infantil
}

\begin{abstract}
Os primeiros narradores são os antepassados anônimos de todos os escritores. O gosto de ouvir é como o gosto de ler. Assim as bibliotecas antes de serem estas infinitas estantes, com as vozes presas dentro dos livros, foram vivas e humanas, rumorosas, com gestos, canções, danças entremeados às narrativas.
\end{abstract}

Cecília Meirelles, 1984.

Pela epígrafe, já podemos ter uma ideia da dimensão e história das narrações. A arte de narrar histórias é uma forma quase artesanal de comunicação, que se perde num passado remoto. $\mathrm{O}$ filósofo alemão Walter Benjamin vê na figura do narrador um homem cujo senso prático nato o habilita para essa arte que tem em sua essência uma dimensão utilitária, mesmo que nem sempre explícita. "Essa utilidade pode consistir seja num ensinamento moral, seja numa sugestão prática, seja num provérbio ou numa norma de vida - de qualquer maneira, o narrador é um homem que sabe dar conselhos" (BENJAMIN, 1986, p. 200) e, nesse sentido, ele se aproximaria dos mestres e dos sábios, uma vez que, como eles, possui um vasto repertório de experiências, ao qual recorre oportunamente enquanto vai fiando suas narrativas, mesmo que estas experiências sejam apropriações de experiências alheias. Fiar e tecer a trama narrativa, num processo incessante de recriação. Esta é a arte de contar histórias, que sempre, foi, na verdade, a arte de recontá-las, pois o narrador deve adaptar aos seus próprios ouvintes os temas e as experiências herdadas, de forma 
que a especificidade do tempo e do lugar possa ser reconhecida por meio da universalidade do motivo (BENJAMIN, 1986).

Sem o apoio da escrita, as narrativas orais foram vencendo os séculos, passando de geração a geração, graças à utilização de recursos típicos da linguagem oral, como a repetição, a rima, as frases estereotipadas, e outros auxiliares mnemônicos, e quando "a memória falhava, entrava a imaginação para suprí-la e a imaginação era o que povoava de seres o seu mundo" (JESUALDO, 1993, p. 106). Contava-se e ouvia-se para satisfazer a "[...] íntima sede de conhecimento e instrução que é a própria da natureza humana. Enquanto se vai contando, passam os tempos do inverno, passam as doenças e as catástrofes [...]" (MEIRELES, 1984, p. 49).

Entretanto, lastima Benjamin, o hábito de narrar foi sendo perdido até encontrar seu esfacelamento em virtude de uma perda de referências coletivas, que interrompe a transmissão da sabedoria. A arte de narrar estaria em extinção, segundo o filósofo, pois as experiências, situações carregadas de sabedoria e fonte de todos os narradores, esgotaram-se, deixaram de ser comunicáveis, intercambiáveis, tornando-se cada vez mais individuais e, portanto, cada vez mais intransferíveis...

Numa época em que não há mais tempo nem espaço para contar ou ouvir histórias, seja em roda de fogo, como os nossos antepassados, seja no convívio familiar, mais presentemente, o narrador perde a função social. Aconselhar torna-se uma prática obsoleta, pois o conselho, continua o filósofo, é uma sugestão para a continuidade da história que está sendo contada e quando não se consegue mais colocar em palavras as experiências, cessa-se a partilha, interrompe-se a história e silencia-se o narrador.

Seria ingênuo, porém, apontar uma única causa para o gradual silenciar dos narradores. Benjamin acredita tratar-se de uma confluência de fatores, traduzidos pela era moderna, que provocaram drásticas e, por que não dizer, 
traumáticas mudanças culturais ocorridas, principalmente, em virtude de uma evolução das forças produtivas: a organização capitalista do trabalho entrecorta o tempo e lança no anonimato as experiências dos homens e suas vozes.

Entre os fatores enumerados por Benjamin, está a primeira Guerra Mundial, da qual os homens voltaram emudecidos,

[...] sem experiências a compartilhar, nem histórias para contar. A Primeira Guerra manifesta, com efeito, a sujeição do indivíduo às forças todopoderosas da técnica, que só faz crescer e transforma cada vez mais as nossas vidas de maneira tão total e tão rápida que não conseguimos assimilar essas mudanças pela palavra (GAGNEBIN, 1994, p. 67).

Vale ressaltar que a lacuna deixada pela palavra comum, coletiva, contribui sobremaneira para o surgimento do romance, gênero tipicamente burguês consagrado no final do século XIX. O romance origina-se do trabalho isolado de um ser "[...] que não pode mais falar exemplarmente sobre suas preocupações mais importantes e que não recebe conselhos nem sabe dá-los" (BENJAMIN, 1986, p. 201), pois escreve no silêncio, encerrado na solidão, sobre a individualidade dos heróis. Assim, "os valores individuais e privados substituem cada vez mais a crença em certezas coletivas, mesmo se estas não são fundamentalmente criticadas nem rejeitadas. A história de si vai pouco a pouco, preencher o papel deixado pela história comum" (GAGNEBIN, 1994, p. $68)$.

Acrescente-se, que o surgimento do romance impõe a primazia da palavra escrita sobre a oral, uma vez que o nascimento desse gênero literário está intimamente vinculado ao livro, à palavra impressa, sendo, portanto, contrário à narrativa, oral em sua essência. A palavra impressa favoreceu outra forma de comunicação, mais ágil que o romance: a informação. O homem das modernas sociedades capitalistas ficou, repentinamente, exposto a uma profusão de informações e ao senso de imediatismo que elas suscitam, situações que contribuíram de forma decisiva para o fim da narrativa, de acordo com 
Benjamin. É esse contexto de narração que se apresenta ao narrador Carlinhos do livro Menino de Engenho de José Lins do Rego, o qual elabora a imagem do engenho como "de um conto de fadas, de um reino fabuloso" (REGO, 2005, p. 42). À primeira vista, a realidade vai comprovando a fantasia. Lá, está também, a velha Totonha com suas histórias fabulosas que encantam o narrador. Sempre que esta passava pelo engenho era uma festa. Suas histórias de reis e rainhas comoviam. Ela sabia como ninguém, contar uma história. Mas

[...] o que fazia a velha Totonha mais curiosa era a cor local que ela punha nos seus descritivos, como por exemplo, $[. .$.$] os rios e as florestas por onde$ andavam os seus personagens se pareciam muito com o Paraíba e a Mata do Rolo. O seu Barba Azul, era o senhor do engenho de Pernambuco (REGO, 2005, p. 80).

Da mesma forma, remeto-me à personagem Sarah, que no filme $A$ Princesinh $a^{3}$, contava histórias fabulosas indianas as suas amigas no internato, o mesmo a que estava submetida em função da ida de seu pai à guerra. São conexões e intertextualidades da literatura com o cinema que precisam ser relacionadas a fim de compreender as tramas da realidade com a fantasia.

Nesse sentido, afirma Anne-Marie Chartier, que "os saberes do futuro são saberes escritos" (CHARTIER, 1999, p. 68) e sua transmissão dar-se-á, primordialmente, "através do livro, que deve pouco a pouco lançar às trevas, as transmissões orais" (IDEM, 1999, p. 68), aprisionando-as dentro em suas páginas. Tornadas eternas no papel, as narrativas orais passam a compor o corpus da chamada Literatura Tradicional, e o que antes era aprendido por ouvir contar, passará a ser aprendido pela leitura.

A Literatura Infantil talvez seja o gênero que mais guarde proximidade dessas narrativas orais que tanto encantaram os homens, pois "é inegável que grande parte da narrativa infantil manifesta ainda aquela 'autoridade' do contador que efetivamente possui experiência comunicável e a sageza que dela

\footnotetext{
${ }^{3}$ Refiro-me ao filme A PRINCESINHA de 1995, dirigido por Afonso Cuarón.
} 
decorre" (BENJAMIN, 1986, p. 210), por isso essa literatura foi capaz de manter "aceso o facho de uma longa tradição milenar de contar histórias" (DIOGO, 1994, p. 37), nas quais o mito, a lenda, o conto de fadas permanecem vivos tal qual estavam narrativas orais dos contadores ancestrais. Depois de terem exercido sua função civilizadora e formadora, essas histórias orais, que contêm experiências da humanidade, se transformaram em obras imortais da literatura universal quando perpetuadas em livro.

\section{A infância em menino de engenho}

Era então a indústria o doce esforço, que hoje nos parece de brinquedo, dos engenhos movidos à mão ou à roda d'água ou a giro de animais. E os desenhos de Frans Post animam figuras de negros trabalhando no meio daquelas rudes fábricas de aquedutos de pau ou tangendo os carros de boi cheios de cana madura.

Gilberto Freyre, 1985.

Este enfoque, também, surge a partir da leitura do livro Menino de Engenho (REGO, 2005) de José Lins do Rego. O tema da infância é o que aguça o desenvolvimento deste artigo, e tal movimento se dá, principalmente, nas relações acentuadas de "poder" do menino de engenho sobre o moleque, as narrativas ouvidas e a importância do brinquedo na infância e suas influências na personalidade da criança.

Tais relações são evidentes e tornam-se mais compreensíveis a partir do aparecimento do conceito de infância. Esse iniciou no século XIII, mas só nos séculos XVI e XVII é que o desenvolvimento dessa concepção apareceu como grande destaque nas obras dos pintores, os quais retrataram alguns momentos desse período.

As primeiras crianças que chegaram à América com a expansão marítima portuguesa sofreram toda uma série de violências. Além de terem sido 
deslocadas de seu ambiente natural, passaram por outros constrangimentos, como fome, medo diante das dificuldades com que eram feitas as viagens e abusos sexuais causados pelos adultos.

Philippe Ariès (1981), no livro História Social da Criança e da Família, irá traçar a "linha do tempo infantil", mostrando o desenvolvimento da criança desde a Idade Média até os nossos dias. Foi com a constituição da família nos séculos XVIII e XIX que a criança passou a ser vista de maneira diferente pela sociedade e foi, também, com o início da melhora das condições sociais que esse quadro assume uma nova moldura.

Se ainda no começo do século XIX sentimos um deslocamento da realidade infantil em relação à sociedade, isso é causado pela acentuada pobreza na maioria das sociedades. Ora, se pensarmos a realidade dos países pobres, e nesse panorama o Brasil se insere, chegaremos à conclusão de que a realidade da infância é uma possibilidade praticamente do pós-guerra. É com as melhorias sociais, muito mais acentuadas nesse período que teremos condições de vislumbrar uma infância tomada pelos brinquedos, ainda que sejam os mais simples, como o pião, o papagaio (ou pipa) e as brincadeiras, que só estão presentes numa infância livre, distante do trabalho.

O desenvolvimento da infância, com suas angústias, suas brincadeiras e seus brinquedos dessa época retratada anteriormente, pode ser claramente percebido no livro Menino de Engenho, de José Lins do Rego. Como o próprio nome engenho sugere, além da já conhecida moenda de cana-de-açúcar, podemos ter o significado de faculdade inventiva, talento, assim, como o próprio título da obra pode associar-se à ideia da infância, representada na figura do menino com suas invenções, seus talentos. Carlinhos, protagonista do romance, desde o contato com o processo do engenho do seu avô, irá estabelecer uma relação com o mecanismo deste: 
Não sei por que os meninos gostavam tanto de máquinas. Minha atenção inteira foi para o mecanismo do engenho. Não reparei mais em nada. Volteime inteiro para a máquina, para as duas bolas giratórias do regulador [...] (REGO, 2005, p. 59-60).

Esse momento surge com a morte da mãe, e sua nova casa, que passa a ser o Engenho Santa Rosa. O menino distante do mundo dos pais, transitando entre a senzala, o mundo dos moleques e a casa-grande, irá formar uma imagem da infância na qual a presença desses elementos serão a marca do adulto. Quando Carlinhos chega a Santa Rosa, um mundo de possibilidades se levanta diante de suas vistas. $\mathrm{O}$ contato com os moleques e as primeiras brincadeiras no pomar do engenho são indícios de como é sua vida na fazenda:

Os moleques estavam me esperando, mas não se aproximavam de mim. Desconfiados, eles olhavam para o meu pijama, para os meus alamares, encantados, com a minha roupa. Porém aos poucos foram se chegando, que pela tarde já estavam de intimidade. E fomos à horta para tirar goiabas e jambos. O que chamavam de horta era um grande pomar. Muito de minha infância eu iria viver por ali, por debaixo daquelas laranjeiras e jaqueiras gordonas (REGO, 2005, p. 58).

A imaginação é um dos elementos essenciais à vida infantil. Para viver intensamente a infância é preciso criar fantasias capazes de transpor as realidades. Os brinquedos sem a imaginação. Praticamente são elementos mortos no mundo das crianças. Muitas vezes, as crianças se utilizam de fatos reais para criarem seus divertimentos. O episódio do cangaceiro Antônio Silvino, em visita ao Engenho Santa Rosa, é um exemplo desta possibilidade de associação entre o real e o imaginário:

Para os meninos, a presença de Antônio Silvino era como a de um rei de nossas histórias, que nos marcasse uma visita. Um dos nossos brinquedos preferidos era até o de fingirmos de cangaceiros, com espada de pau e capacetes no ombro, e o mais forte dos nossos fazendo de Antônio Silvino (REGO, 2005, p. 65). 
A mesma presença dos brinquedos é constante no romance. Muitas vezes o brinquedo aparece entrelaçado ao rancor dos adultos. Na infância de Carlinhos é marcante a figura da velha Sinhazinha. Uma personalidade que transita entre a bondade com algumas pessoas e a perseguição para com outras que não simpatiza. Ao que vemos, o menino está na lista dos perseguidos, e isso, entre muitos outros momentos, pode ser percebido na passagem em que Carlinhos leva uma surra da velha, causada por uma brincadeira com o pilão:

Numa ocasião, jogando pião na calçada, o brinquedo foi cair em cima de seu pé. A velha levantou-se com uma fúria para cima de mim, e com o seu chinelo de couro encheu-me o corpo de palmadas terríveis. Bateu-me como se desse num cachorro, trincando os dentes de raiva. E se não fosse a Tia Maria que me acudisse, ela teria me despedaçado (REGO, 2005, p. 68-69).

Apesar das dificuldades da infância de Carlinhos, podemos verificar momentos de descontração, de alegria e de uma vida infantil regada de vontades e de travessuras. Vários são esses quadros que José Lins nos proporciona. Entre eles, é possível citar o momento da cheia do rio Paraíba, verdadeiro pânico para os habitantes de Santa Rosa, contudo instantes de grandes divertimentos para Carlinhos e seus amigos. As conversas das negras da casa-grande, as negras da cozinha com suas histórias de assombrações, é outro momento marcante na infância do menino. A crença nos bichos perigosos do engenho é tristemente desfeita, palavras do próprio Carlinhos, quando tem contato com o catecismo.

Mesmo assim, o menino afirma que muita coisa desse mundo das histórias de mal-assombrados ficou registrada na pessoa do homem Carlinhos. A imagem da senzala tem uma função importante na infância do menino, apesar desse cenário ser posterior à escravatura, ainda restava a senzala dos tempos do cativeiro. Carlinhos relata com forte expressão de detalhes esse quadro da senzala. Segundo o menino, as negras, mesmo depois da escravidão, continuavam no engenho vivendo da mesma maneira anterior. Morriam de velhas, trabalhando para o Senhor e recebendo o que vestir e comer. A 
contribuição que a escravidão fornece ao mundo dos brancos é muito maior do que parece.

Analisando as relações estabelecidas desde o começo do processo, com as negras servindo de reprodutoras, as quais ajudam a manter todo o sistema, podemos perceber que os negros foram o braço forte na formação da estrutura econômica e social brasileira. Além das negras, os moleques participavam ativamente. O sofrimento causado pelos meninos da casa-grande tem períodos de desforra por parte dos moleques. O autor José Lins pontua esse instante de realização do moleque diante dos meninos brancos, mostrando que a imposição dos que sabem fazer, e no caso dos que sabiam melhor todas as brincadeiras, era a alternativa de força imposta dos fracos sobre os fortes. Tal imposição é acentuada nas trocas estabelecidas pelos moleques: "Pediam-nos para furtar coisas da casa-grande para eles: laranjas, sapotis, pedaços de queijo. Trocavam conosco os seus bodoques e os seus piões pelos gêneros que roubávamos da dispensa" (REGO, 2005, p. 92).

É evidente que, apesar dessas relações, a vida do negro, do moleque, era muito inferior em comparação com a vida do menino da casa-grande. Nas descrições do romance, são fortemente acentuadas as dificuldades da vida dos meninos negros. O não acesso ao mundo dos "brinquedos infantis" (BENJAMIN, 1984) é uma espécie de denúncia feita por José Lins através do menino. Quando Carlinhos sai com a Tia Maria para passar o dia no oiteiro, vemos no percurso da viagem a inferioridade dos vários mundos que compõem a vida das crianças da mesma faixa etária do protagonista. A parte da narrativa que mais desperta essa visão é quando as crianças se aproximam da madrinha (a Tia Maria) para tomar a benção:

- Deus te abençõe.

E eram mesmo abençoados por Deus, porque não morriam de fome e tinham o sol, a lua, o rio, a chuva e as estrelas para brincadeiras que não se quebravam (REGO, 2005, p. 97, grifos nossos). 
A diferença entre a vida de Carlinhos e desses afilhados da Tia Maria merece atenção especial. $\mathrm{O}$ mundo da natureza também fazia parte do mundo de Carlinhos. No entanto, outros fatores, como os brinquedos, contribuíam para compor essa infância. $\mathrm{O}$ que percebemos na descrição acima é a ausência dos brinquedos. Os afilhados da Tia Maria recebem a bênção da madrinha, porque diante de tanta privação, conseguem sobreviver, não morrem de fome e ainda têm os elementos inquebráveis da natureza a lhes servirem de brinquedos (PORTO, 2005).

A maneira como está narrado esse episódio nos faz pensar nos mundos diversos e pouco ou muito enriquecidos, que dão forma à infância das crianças. $\mathrm{O}$ autor José Lins acentua, por meio de sua escrita, uma carga de revolta diante das várias realidades da sua infância. $\mathrm{O}$ sol, a lua, o rio, a chuva e as estrelas não se quebram, mas são brinquedos muito diferentes dos piões, dos papagaios, dos bodoques, entre outros.

Há, porém, outros aspectos que compõem o seu mundo infantil. A presença dos sonhos na infância é uma marca constante. Muitas vezes, mesmo percebendo a dificuldade de realização, as crianças alimentam os sonhos, depositando toda uma carga de sentimentos na tentativa de alcançá-los. Um fator que dificulta a realização dos sonhos é o acesso ao poder do mercado.

Com a distância, cada vez mais acentuada, do poder de consumo, notamos que os velhos sonhos infantis permanecem na esfera psicológica, e os males causados pela não realização pode ser motivo de muitas incompreensões pelos adultos. No romance Menino de Engenho, Carlinhos nos mostra o "desenrolar" do processo de um sonho e a felicidade de ter conseguido alcançá-lo:

Comecei então a alimentar o sonho de ser dono também de um cavalinho daquele. E um sonho de menino é maior do que de gente grande, porque fica mais próximo da realidade. O meu tomara conta de todas as minhas faculdades. E de tanto pedir, eu entrara na posse do objeto sonhado. Já tinha o meu carneiro Jasmim. Faltaram-me a sela e os arreios. Sonhei também 
noites inteiras com o meu corcel todo metido nos seus arreios de luxo. Queria-os, e, por fim, mandaram fazê-los em Itabaiana (Rego, 1987: 103).

A distinção entre o mundo de Carlinhos e o de outras crianças, como por exemplo, os afilhados da Tia Maria, descritos em parágrafo anterior, é que esses, mesmo depositando toda a carga de esperança nos sonhos, não conseguem alcançá-los; enquanto aquele, em pouco tempo, e com uma dose de insistência, consegue o objeto sonhado. É a realidade das diferenças, com suas distâncias e suas impossibilidades de aproximação.

Se, de um lado a infância está sombreada desse mundo dos brinquedos; de outro, a transição desse mundo para a adolescência, por volta dos doze ou treze anos, está marcada pela iniciação sexual. Em Menino de Engenho, o personagem Carlinhos é antecipadamente iniciado no mundo do sexo, e isso se dá em torno dos oito anos de idade. Fazemos aqui referência à poesia "Meus Oito Anos" de Casimiro de Abreu e a nostalgia da visão romântica das crianças dos tempos passados.

Desde os primeiros contatos do menino com o mundo do engenho, verifica-se um olhar voltado para o mundo do sexo. É por meio dos relatos das experiências dos moleques, que o sobrinho da Tia Maria vai, pouco a pouco, tomando conhecimento desse novo mundo. O próprio Carlinhos expressa o crescimento da vontade pelo sexo, afirmando que os seus impulsos tinham mais anos que a sua idade e o sexo crescia nele mais depressa do que as pernas e os braços. A transição de Carlinhos do mundo dos brinquedos para a vida sexual tem a negra Luisa como par. É essa que irá marcar esse momento da vida do menino. Quando Luisa engravida de outro homem, Carlinhos estabelece os encontros com a rapariga Zefa Cajá:

Tinha uns doze anos quando conheci uma mulher, como homem. Andava atrás dela, beirando a sua tapera de palha, numa ânsia misturada de medo e de vergonha. Zefa Cajá era a grande mundana das cabras do eito. Não me queria. 
- Vá se criar, menino enxerido.

- Mas eu ficava por perto, conversando com ela, olhando para a mulata com vontade mesmo de fazer coisa ruim. Ficou comigo uma porção de vezes (REGO, 2005, p. 134).

Após esse contato com a rapariga, o menino acaba adquirindo "doença do mundo" (REGO, 2005, p. 136). Esse novo acontecimento na vida de Carlinhos, servindo também de risos por parte dos adultos, foi o que determinou a sua ida para o colégio, fechando definitivamente o ciclo da infância do mundo do engenho, com suas brincadeiras, com seus brinquedos. Assim, penso que todo o trajeto da vida infantil, com suas aventuras, suas realizações, suas alegrias, são fatores que contribuirão para a formação do adulto.

Por último, para finalizar este item que trata da concepção de infância em Menino de Engenho, resolvemos fazer algumas considerações a partir dos desdobramentos citados anteriormente. A primeira delas se refere ao ambiente da infância, quando ao imaginarmos tal ambiente, vemos a importância da vida infantil, com o afastamento de olhar necessário pelos adultos, fato tão incomum nas sociedades modernas. Dessa forma, a infância pode ser melhor vivida, melhor trabalhada pelas crianças. É possível que agindo assim, tenhamos adultos menos comprometidos, mais dispostos ao trabalho do dia-a-dia, mais crentes ou cientes na utopia. A segunda delas, refere-se ao fato de que é necessário ter clareza e consciência de que não existe uma forma única de ser criança ou uma infância universal para poder olhar os sujeitos que corporificam essa categoria e suas múltiplas formas de vivê-la, indo além dos conceitos sedimentados em nosso meio social.

$\mathrm{Na}$ tentativa de quebrar esses dois paradigmas, existe uma possibilidade de buscarmos o jeito de ver e pensar das crianças com o auxílio do "Terceiro Olho" (JUNQUEIRA, 1985, p. 175), aquele que domina os conhecimentos científicos, e que prima por perceber o intelecto e conjugá-lo com a alma humana (a visão interior e pela inspiração intuitiva). Uma alma que lhe é dada 
(entre outros elementos) pela cultura, como diz a antropóloga Carmem Junqueira (1985). É igualmente possível modelar esse olhar de forma que se consiga perceber as infâncias e os sujeitos que compõem essa categoria social de maneira diversa e instável, e que se revelam como algo "que encarna a aparição da alteridade", como dizem Larrosa e Lara (1998, p.70).

\section{A Superação da Infância - Indo à Escola}

Não se pode "descolar" o signo da memória e o signo do regionalismo em Menino de Engenho, obra romanesca de José Lins do Rego. Nele, num depoimento pessoal que traz elementos autobiográficos, o autor fixa o esplendor do engenho de açúcar com sua estrutura feudal e patriarcal que caracterizou a paisagem agrária nordestina no século passado. A problemática apresentada, como sugere o título, Menino de Engenho, pode ser analisada de duas perspectivas: a realidade do mundo rural do engenho e a educação, nesse contexto, do menino de engenho. Aliás, essa era a intenção expressa do autor. José Lins desejava, como ele mesmo confessou, "traçar a biografia de seu avô, o velho José Lins" (REGO, 2005), que era para ele o tipo representativo do senhor de engenho, expressão legítima do patriarcalismo rural da região açucareira do Nordeste. O mundo evocado em Menino de Engenho, pois, é o latifúndio do engenho de açúcar em todo o seu esplendor e opulência. Em torno dele, evidentemente, gira todo um mundo social, quase sempre de penúria e miséria, representado por trabalhadores de eito, moleques da cozinha ou das senzalas e até mesmo pela prostituição.

É no entrecruzamento de narrações, brincadeiras, porcarias, depravações e sexo, que o menino de engenho cresce solto, na ampla liberdade do latifúndio. Não existe na casa grande uma preocupação em pôr limites, e a criança vai 
crescendo livremente, à solta, sem nenhum policiamento e sem os freios até mesmo da religião, praticamente inexistente no mundo do engenho. Assim, libertino e depravado, ele acaba indo para a escola. Lá, certamente, ele "endireitaria", pois esta é vista como uma "casa de correção: - Colégio amansa menino" (REGO, 2005, p.147). Assim é vista a escola daquela época. E hoje, algo mudou?

Com certeza muitas práticas mudaram. Neste artigo, aliados ao contexto de surgimento da Literatura Infantil, propomo-nos a refletir sobre alguns conceitos de infância em diálogo com as relações de "poder" do menino de engenho sobre o moleque, com as narrativas e a importância do brinquedo na infância naquela época. Como proposição futura para um próximo artigo, nossa intenção é problematizar a infância não só pelos aspectos culturais presentes na literatura infantil, mas a partir de sua relação com as tecnologias. Em outras palavras, mais uma concepção de infância: o surgimento de uma ciberinfância, termo utilizado por Dornelles (2005), a qual busca investigar a relação das crianças com o seu cotidiano num contexto em que as tecnologias e a internet emergem que sujeitos capazes de acessar e manipular recursos tecnológicos com tanta facilidade e originalidade, denominados de geração nativos digitais, expressão criada por Marc Prensky (2001). Essa infância sim, talvez possa se traduzir como sendo uma das várias infâncias que constituem a nossa sociedade na contemporaneidade e da qual precisamos explorar mais a fim de compreender os novos desdobramentos culturais e sociais da educação, as demandas de novas formações aos educadores para lidar com a ciberinfância, os softwares, os jogos e sites que estão tanto atraindo as crianças nas redes sociais e como potencializar o uso desses artefatos para a educação. 


\section{Referências}

ARIÈS, Philippe. História Social da Criança e da Família. Tradução Dora Flaksman. Rio de Janeiro: Livros Técnicos e Científicos, 1981.

BENJAMIN, W. O Narrador: considerações sobre a obra de Nikolai Lescov. In: BENJAMIN, W. Obras Escolhidas. Magia e Técnica, Arte e Política. 2. ed. - Tradução: Sérgio P. Rouanet. São Paulo: Brasiliense, 1986. v. I, p. 200-215.

. Reflexões: a criança, o brinquedo, a educação. Tradução Marcus Vinicius Mazzari. São Paulo: Summus, 1984.

CHARTIER, A. M. Leitura e Saber ou a Literature Juvenile entre Ciência e Ficção. In: MARTINS, A. A. et al. A escolarização da Leitura Literária. Belo Horizonte: Autêntica, 1999. p. 60-75.

DIOGO, A. A. L. Literatura Infantil: histórias, teoria, interpretações. Porto: Porto, 1994.

DORNELLES, L. V. Infâncias que nos Escapam: da criança na rua à criança cyber. Petrópolis, RJ: Vozes, 2005.

FREYRE, G. Nordeste: Aspectos da influência da Cana sobre a Vida e a Paisagem do Nordeste do Brasil [1937]. Rio de Janeiro/Recife: José Olympio Editora/FUNDARPE, 1985.

GAGNEBIN, J. M. História e Narração em Walter Benjamin. São Paulo: Perspectiva/FAPESP, Campinas: Editora da UNICAMP, 1994.

JESUALDO, J. A Literatura Infantil. Tradução: James Amado. São Paulo: Cultrix, 1993.

JUNQUEIRA, C. Em Trânsito: preparando a mudança. In: ABRAMOVICH, Fanny (org.) Ritos de Passagem de Nossa Infância e Adolescência: Antologia. SP: Summus, 1985. p, 171-180.

LARROSA, J. e LARA, N. P. de. (orgs.) Imagens do Outro. Petrópolis, RJ: Vozes, 1998.

MEIRELES, Cecília. Problemas da Literatura Infantil. 4. ed. Rio de Janeiro: Nova Fronteira, 1984.

PORTO, C. P. Brinquedo e Brincadeira na Brinquedoteca. In: KRAMER, S. \& LEITE, M. I. (orgs), Infância e Produção Cultural. 4. ed. Campinas: Papirus, 2005. p. 171-198.

PRENSKY, Marc. Digital Natives, Digital Immigrants. MCB University Press, 2001. Disponível em: <http://www.marcprensky.com/writing/Prensky\%20\%20Digital \%20Natives,\%20Digital\%20Immigrants\%20-\%20Part1.pdf>. Acesso em: 26 ago 2012.

REGO, J. L. do. Menino de Engenho. 90. ed. Rio de Janeiro: José Olympio, 2005. 